\title{
Mathematical modeling of an innovative hybrid solar-gas dryer
}

\author{
Ahmed Zoukit \\ LSET, Applied Physics Department, FST, Cadi Ayyad University, Marrakesh, Morocco, \\ ahmed1991zoukit@gmail.com, ORCID: 0000-0001-5406-6038 \\ Hicham El Ferouali \\ LSET, Applied Physics Department, FST, Cadi Ayyad University, Marrakesh, Morocco, \\ hichamelferouali@gmail.com. ORCID: 0000-0001-7541-4193
}

Issam Salhi

LSET, Applied Physics Department, FST, Cadi Ayyad University, Marrakesh, Morocco, isalhi@yahoo.fr. ORCID: 0000-0001-8399-7827

\section{Said Doubabi}

LSET, Applied Physics Department, FST, Cadi Ayyad University, Marrakesh, Morocco, s.doubabi@ac.ma. ORCID: 0000-0001-9947-5206

Naji Abdenouri

LSET, Applied Physics Department, FST, Cadi Ayyad University, Marrakesh, Morocco, n.abdenouri@uca.ma. ORCID: 0000-0002-9399-5435

\section{Arrived: 06.09.2018 Accepted: 01.12.2018 Published: 31.12.2018}

\begin{abstract}
This paper is devoted to develop a multivariable model (MM) of an innovative hybrid solar-gas dryer issued from a CFD study. The proposed (MM) was explored to predict the drying chamber temperature in forced convection $(0.025 \mathrm{~kg} / \mathrm{s})$ in two main operating modes (solar mode and gas mode). There is an indirect heating of drying air instead of direct heating inside the drying chamber as it was reported in conventional hybrid solar-gas dryers. CFD technique was used to simulate the temperature and airflow distribution inside the drying chamber. However, CFD simulation requires huge capacity of the processor for calculating and takes significant simulation time. Therefore, the multivariable model was developed to predict the drying temperature instantly with a notable reduction in simulation time. Root Mean Square (RMSE) was used to measure the difference between the predicted values by CFD and (MM) model. It was found that the results shown fairly good agreement with an RMSE lower than 2.35 confirming the pertinence of the proposed model. The developed model led to a quick output parameters estimation related to each climatic condition. Thus, it is very useful for synthesizing a control system of the temperature as well as the optimization of gas consumption.
\end{abstract}

Keywords: $\quad$ Renewable energy, Hybrid solar-gas dryer, Least squares methods, CFD, Drying temperature

Cite this paper as:

Zoukit, A., El Ferouali, H., Salhi, I., Doubabi, S., Abdenouri, N. Mathematical modeling of an innovative hybrid solar-gas dryer. Journal of Energy Systems, 2018; 2(4): 260276, DOI: 10.30521/jes.457647

(C) 2018 Published by peer-reviewed open access scientific journal, JES at DergiPark (www.dergipark.gov.tr/jes)

\begin{tabular}{r|l} 
Nomenclature & \\
$T_{c h}$ & Drying chamber temperature $\left[{ }^{\circ} \mathrm{C}\right]$ \\
$T_{a}$ & Ambient temperature $\left[{ }^{\circ} \mathrm{C}\right]$ \\
$G$ & Solar radiation $\left[\mathrm{W} / \mathrm{m}^{2}\right]$ \\
$P_{g}$ & Gas power $[\mathrm{W}]$ \\
$\dot{m}$ & Airflow $[\mathrm{kg} / \mathrm{s}]$ \\
\hline
\end{tabular}




\section{INTRODUCTION}

Application of solar energy has been old since the existence of human being. Therefore, in order to maintain a safe environment, considering alternate renewable energy sources has become an essential mission [1]. Along the time, drying process usually requires much energy, the uncontrolled conditions favor the loss of product quality and also require a continued supplying energy. Drying is also one of the major preservation methods, has been utilized for centuries for valorizing and preserving the product for a long time. It is one of the oldest techniques and important prerequisites utilized by humankind to reduce sufficiently the water activity of food commodities in order to prevent microbial growth [2]. Drying improves the product's shelf life and storage durability, diminishes wastes and transportation costs [3]. Generally, drying occurs by mass transfer operation including the removal of water from a material by evaporation [4]. This latter, has several disadvantages associated with cost of equipment, the quantity and cost of consumed energy [5,6] and the unevenness drying of the products [7]. In addition, the process is slow and intermittent, highly labor intensive, time consuming, and requires large operational space. Therefore, considerable efforts have been done to look for a compromise for developing a vital solution for drying food commodities.

Indirect solar drying represents a promising alternative that should replace sun drying to cover the increasing demand for healthy, low-cost natural food and the need for sustainable income [8]. Indirect solar drying prevents direct exposure of food products to solar rays and contamination [9].

Solar drying is extended by the presence of another source of energy to overcome the intermittency of solar energy. The second energy source leads also to extend the drying time and to control the drying parameters during the dehydration process. Various type of hybrid solar-gas dryers $[10,11,12]$ have been designed and developed for fruits, vegetables and other agriculture product drying either at industrial scale or by small farmers. Unfortunately, most of these hybrid dryers burn the gas in the same place with the products where the dried product adsorbs the flue gases as shown in Figure 1. During the whole drying process, the surface of the dried product is subjected directly to the flue gases and to the emitted soot due to incomplete combustion. Hence the quality of end-dried products is degraded. The proposed hybrid dryer uses a solar-gas collector as it is shown in Figure. 2. In this new configuration, the gas burners are set up along the rare side of the solar collector. The absorber picks up heat from both sides: on its top side from solar radiation and on its rare side from gas burners. Thus, during daytime, the solargas collector receives the solar radiation for direct heating of drying air. The gas heaters are utilized to maintain the drying process during off-shine hours. The burners are placed outside the drying chamber. They are set up in the solar collector (Figure. 2a), under the absorber. Hence, the flus gases exhausts outside the dryer and are not mixed with the drying air. This results, lead to enhance the quality of enddried products.

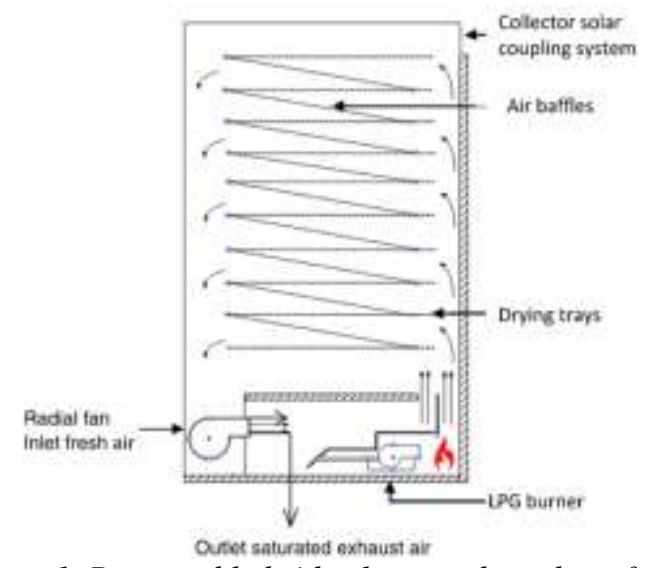

Figure 1. Proposed hybrid solar-gas dryer by ref [11]. 
The air temperature inside the drying chamber is the most important parameter that affects strongly the drying rate. Nevertheless, the fluctuating of weather conditions and the intermittency of solar energy highly affect the threshold of the drying air. Therefore, the quality of dried products can be strongly altered.

For effective use of the hybrid dryer and in order to enhance the quality of the dried products, synthesizing a complete control system of the drying parameters is primordial. To achieve that, prediction model of the output parameters related to input conditions is necessary. Further, reduction in gas consumption can be expected by design optimization and by the operating parameters control of hybrid dryer.

Several previous works employed CFD to simulate the temperature, air velocity and relative humidity at various locations inside the drying chamber $[13,14,15,16]$. However, due to the geometric complexity of the whole dryer, obtaining accurate results by CFD study requires a fairly tight mesh, a high storage capacity and a huge simulation time [17].

On the other hand, predicting output by Matlab software was developed in many previous works $[18,19,20]$. Authors in [18] developed a mathematical model based on mass and heat transfer to predict crops temperature, air temperature, the moisture evaporated and for predicting the thermal performances of a solar dryer. Tiwari et al [19] developed a mathematical model in Matlab based on energy and exergy analysis to estimate the temperature of a greenhouse for fish drying. The necessary input parameters were ambient temperature, solar radiation and ambient relative humidity. The obtained predicted values are closer than those experimentally revealed. The coefficient of correlation and Root mean square error percent deviation are 0.94-0.99 and 2.4-10\%, respectively. In other works, EL Ferouali et al [21,22] developed a mathematical model based on energy balance for investigating the thermal performances of solar air heaters operated in natural and forced convection. The obtained results would be highly informative for designing suitable and performing solar air heaters used in indirect solar dryers. The proposed models were developed for a simple solar dryer but not for hybrid ones.

The main objective of this paper is to simulate an innovative hybrid indirect solar-gas dryer where the operating parameters are easily controlled during whole drying process and for all weather conditions. CFD modeling of the hybrid dryer was preliminary used only in order to investigate its thermal performances in term of the threshold of drying temperature. However, a multivariable model issued from CFD simulation was developed based on nonlinear least squares methods using Matlab system identification (ident). The behavior of the hybrid dryer was modeled in two main operating modes (solar mode where the energy is only provided by solar radiation and gas mode where the energy is only provided by gas power). The innovative developed model based state space leads to predict the drying temperature inside the drying chamber instantly with a huge reduction in simulation time and leads also to easily synthesize a control system of the drying temperature. The model might be handled by a simple calculation support device which could be easily integrated into the hybrid solar-gas dryer.

\section{DESCRIPTION OF HYBRID SOLAR DRYER}

The hybrid solar-gas dryer was designed and simulated using SolidWorks Flow simulation developed by Dassault systems SolidWorks crops (Figure 2). The designed dryer consists of a drying chamber which is the seat of physical operation. The drying chamber contains many trays that will be filled with the products to dry. The drying chamber is linked to a solar-gas collector used to generate the hot airregularly. The collector is a simple pass-finned plate solar air heater. The top side of the absorber is painted with matt black glycerphtalic lacquer (absorptivity $=0.95$, emissivity $=0.8$ ). The collector is covered by a glass (transmissivity $=0.95$ ) with a separation of $5 \mathrm{~cm}$ with the absorber. The solar collector 
is fitted with a heat exchanger (metallic sheet) placed under the absorber. The fresh air is heated when it came in contact with the absorber and the surface of heat exchanger plate. The auxiliary heating system is a set of nine tubular burners located under the heat exchanger and monitored by a proportional valve. A fan was mounted in the chimney of the drying chamber to remove water vapor, ensure a better hot air circulation and uniformity of temperature inside the drying chamber. The gas burners can be used to raise the temperature level to the desired threshold in the case where solar radiation is not sufficient or non-existent. The solar-gas collector is fitted with three apertures in the both sides allowing the entrance of the necessary air required for combustion and an aperture in the outlet of the collector for the exhaust of flue gases.

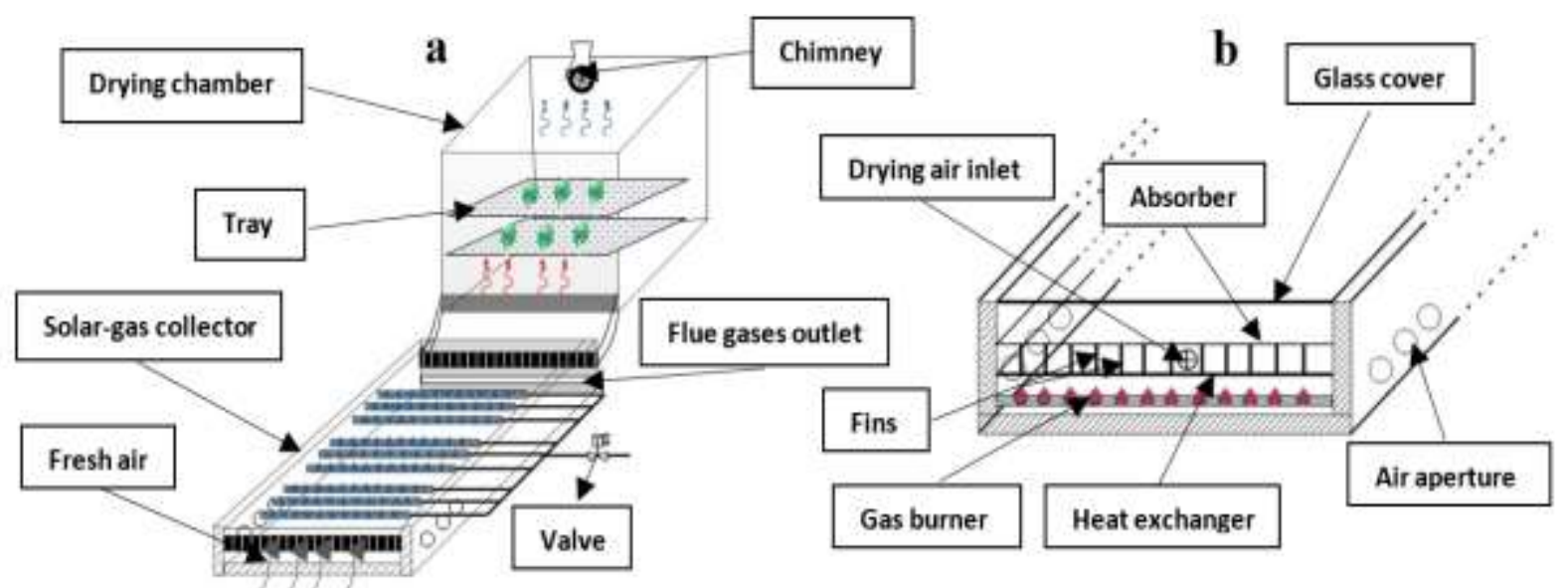

Figure. 2. Synoptic of the hybrid solar-gas dryer: (a) hybrid solar-gas dryer, (b) solar-gas collector.

\section{SIMULATION APPROACH}

CFD was utilized to investigate the distribution of air temperature, relative humidity and airflow inside the drying chamber. Heat transfer in the drying chamber is accomplished by 3-dimentional governing equation (mass, momentum and energy equation) along with initial and boundary conditions under transient and turbulent flow assumptions. The flow was considered as incomprehensible. The stability and accuracy were obtained using $k-\varepsilon$ turbulence model. The wall of the fins was considered quit thick so the internal conduction was assumed negligible. The transient term was implicit. The conservation lows for mass, momentum and energy equations in the Cartesian coordinate system could be written by [17]:

Continuity equation:

$$
\frac{\partial \rho}{\partial t}+\frac{\partial}{\partial x i}\left(\rho u_{i}\right)=0
$$

Momentum equation:

$$
\frac{\partial \rho u_{i}}{\partial t}+\frac{\partial}{\partial t}\left(\rho u u_{i}\right)=-\frac{\partial P}{\partial t}+\frac{\partial \bar{\tau}_{e f f}}{\partial t}+\rho g \beta\left(\bar{T}_{0}-\bar{T}\right)
$$


Energy equation:

$$
\frac{\partial(\rho E)}{\partial t}+\frac{\partial}{\partial t}\left(u_{i}(\rho E+P)\right)=\frac{\partial}{\partial t}\left(\gamma_{e f f} \frac{\partial T}{\partial t}-\sum_{n} H_{n} J_{n}+\left(\bar{\tau}_{e f f} \cdot u_{i}\right)\right)
$$

Where $u_{i}$ is the mean velocity component vector $(\mathrm{m} / \mathrm{s}), E$ is the specific energy of fluid $(\mathrm{j} / \mathrm{kg}), \gamma_{\text {eff }}$ is the effective thermal conductivity $(\mathrm{W} / \mathrm{m} . \mathrm{K}), H_{n}$ is the enthalpy of species $n(\mathrm{~J} / \mathrm{kg}), J_{n}$ is the diffusion flux of species $n\left(\mathrm{~kg} / \mathrm{m}^{2} \mathrm{~s}\right), t$ is the time (s), $\rho$ is the density $\left(\mathrm{kg} / \mathrm{m}^{3}\right), P$ is the pressure $\left(\mathrm{N} / \mathrm{m}^{2}\right), \mathrm{g}$ is the gravitational acceleration vector $\left(\mathrm{m} / \mathrm{s}^{2}\right), \beta$ is the thermal expansion coefficient, $\bar{T}_{0}$ is the system surrounding temperature in the work (reference temperature, $\mathrm{K}$ ), $\bar{T}$ is the mean temperature and $\bar{\tau}_{\text {eff }}$ is the effective stress tensor as Equ [4]:

$$
\bar{\tau}_{e f f}=\mu_{e f f}\left[\left(\frac{\partial u_{i}}{\partial t}+\frac{\partial \bar{u}_{i}^{T}}{\partial t}\right)\right]-\frac{2}{3} \frac{\partial \bar{u}_{i} I}{\partial t}
$$

Where $\mu_{\text {eff }}$ is the effective viscosity ( $\left.\mathrm{kg} / \mathrm{m} . \mathrm{s}\right), \bar{u}_{i}^{T}$ is the transposed mean velocity $(\mathrm{m} / \mathrm{s})$, and $I$ is the unit tensor.

\subsection{Simulation Model}

Figure 3 shows the 3-D solar-gas hybrid dryer simulation model. Geometric parameters and the material properties of the prototype of solar-gas hybrid dryer are given in Table 1 . This model used single component model with assumptions of incompressible and unsteady-state flow [15]. Due to the geometric complexity of the dryer, obtaining accurate results requires a fairly tight mesh, a high storage capacity and a huge simulation time. Simulations were conducted using a grid density of 1906000 elements. This meshing method was set automatically because of the complexity in the drying chamber and the restrict resources. Hence, the number of nodes inside the heat exchanger is $247 \times 247$. The high grid density requires computational resources beyond the availability in the laboratory (Intel core-i7, 3.4GHz, 24GB Ram, 1TB Hard disk).
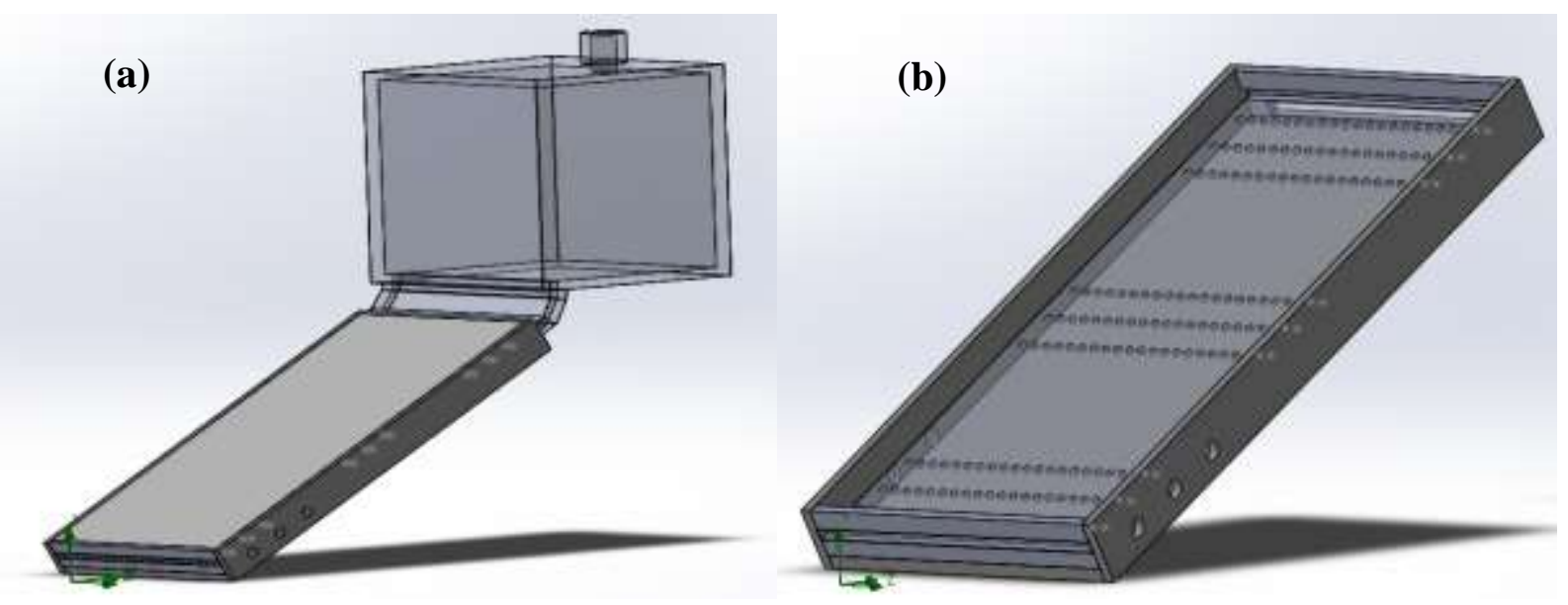

Figure 3. 3D model of hybrid solar-gas dryer: (a) Hybrid dryer; (b) Solar-gas collector. 
Table. 1. Details of components, materials, sizes and material properties of the dryer

\begin{tabular}{|c|c|c|c|c|c|}
\hline \multirow[b]{2}{*}{ Component } & \multirow[b]{2}{*}{ Material } & \multirow[b]{2}{*}{ Size } & \multicolumn{3}{|c|}{ Material property } \\
\hline & & & $\begin{array}{c}\text { Thermal } \\
\text { conductivity }(\mathrm{W} / \mathrm{m} . \mathrm{K})\end{array}$ & $\begin{array}{l}\text { Density } \\
\left(\mathrm{kg} / \mathrm{m}^{3}\right)\end{array}$ & $\begin{array}{c}\text { Specific heat } \\
(\mathrm{J} / \mathrm{kg} . \mathrm{K})\end{array}$ \\
\hline Absorber & Aluminum & $2 \mathrm{~m} * 1 \mathrm{~m}$ & 237 & 2700 & 897 \\
\hline Glass cover & Glass & $2 \mathrm{~m} * 1 \mathrm{~m}$ & 1.05 & 2500 & 670 \\
\hline Heat exchanger & Iron & $2 \mathrm{~m} * 1 \mathrm{~m}$ & 80.2 & 7870 & 447 \\
\hline Gas burner & Iron & $1 \mathrm{~m}$ & 80.2 & 7870 & 447 \\
\hline Sides insolation & Mineral fiber & thickness $50 \mathrm{~mm}$ & 0.035 & 20 & 1030 \\
\hline Bottom insolation & Mineral fiber & thickness $50 \mathrm{~mm}$ & 0.035 & 20 & 1030 \\
\hline Fins & Aluminum & thickness $1 \mathrm{~mm}$ & 237 & 2700 & 897 \\
\hline Air aperture & Mineral fiher & diameter $5 \mathrm{~cm}$ & 0035 & 20 & 1030 \\
\hline
\end{tabular}

\subsection{Initial and Boundary Conditions}

At the initial state, the temperature of the chamber walls, the surface of tubular burners and the air inside chamber were assumed to be at $25^{\circ} \mathrm{C}$. Boundary conditions including inlet air velocity, temperature, humidity, and outlet pressure are given in Table 2 . The inlet air velocity was calculated from the flow rate of the ventilating fan while the inlet temperature and relative humidity were assumed to be constant at $25^{\circ} \mathrm{C}$ and $50 \%$ respectively, which were typical average ambient temperature and relative humidity in Marrakesh city in Morocco. The emitted flames from burners are modeled as volume heat sources located under a metallic sheet. The diameter of the flames was considered $1 \mathrm{~cm}$ and their number is 216 (24 flame for each burner). Hence, the power of each flame is $P_{g} / 216$, with $P_{\mathrm{g}}$ is the total gas power (W).

Table. 2. Boundary conditions performed in simulation

\begin{tabular}{ll}
\hline Parameter & Value \\
\hline Inlet air velocity $(\mathrm{kg} / \mathrm{s})$ & 0.025 \\
Inlet air temperature $\left({ }^{\circ} \mathrm{C}\right)$ & $25^{\circ} \mathrm{C}$ \\
Outlet pressure $(\mathrm{Pa})$ & $101325 \mathrm{~Pa}$ \\
Inlet air humidity $(\%)$ & 50 \\
\hline
\end{tabular}

\section{MULTIVARIABLE MODELING}

The state space approach (proposed since 1960) was used for the first time to solve general linear multivariable modeling and control systems. This branch of automatic control has been very actively developed in the last three decades with many published papers in the topic. It is based on linearization of non-linear system around operating point and developing a linear model representing its behavior in a specific operating range.

Process identification is the field of mathematical modeling using test data. System identification is defined by Zadeh (1962) as: the determination of the system's model on the basis of input and output data. The input-output data are usually collected from an identification test or experiment that is designed to make the considered data maximally informative about the system properties [23,24]. A set of candidate models is obtained by specifying their common properties and finally a suitable model is searched for within this set [25]. 
In this study, a hybrid solar-gas dryer investigated and designed. The experimental tests and the simulation performed highlight the nonlinear behavior of the multivariable system (dryer). However, the system can be linearized around many operating points.

Solar radiation $(G)$, airflow $(\dot{m})$ and gas power $\left(P_{g}\right)$ are considered as the main inputs of the dryer and the drying chamber temperature $\left(T_{c h}\right)$ is considered as the output parameter. The humidity of air inside the chamber was considered the same as the ambient one (in the unload case) and the ambient temperature $\left(T_{a}\right)$ is considered as a perturbation measurement (Figure 4).

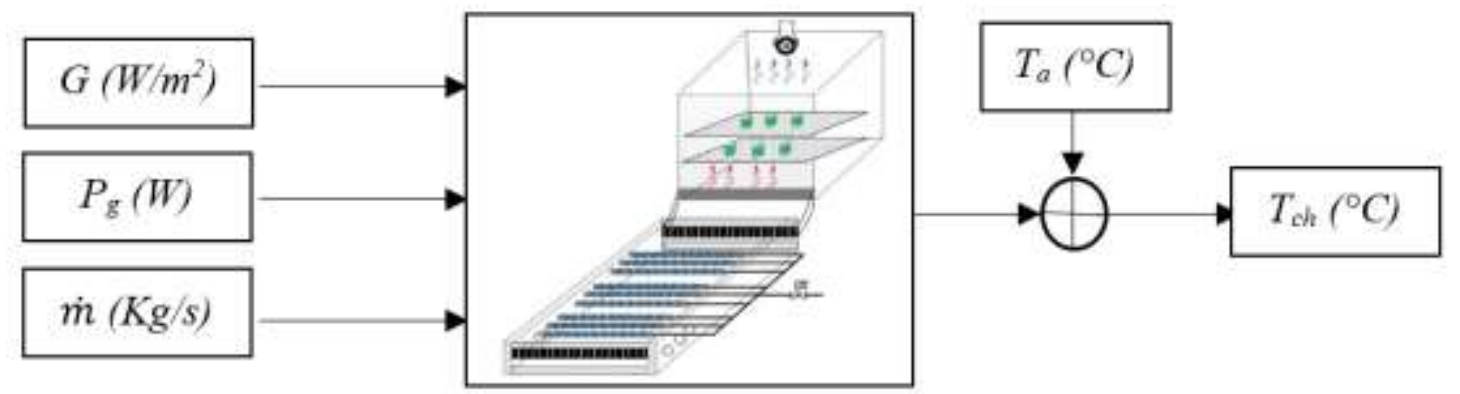

Figure 4. Input/output of the dryer.

\subsection{Static Characteristics}

To get the static characteristics of the dryer, the output parameter (drying temperature) was measured on the basis of input parameters (solar radiation, gas power and airflow) during the steady state. Therefore, the static characteristics allow to figure out the dryer's input/output relationship and then give a general idea about the linearity and non-linearity of the system behavior. And especially, identifying the linear zones and operating points.

The average drying temperature $\left(T_{c h}\right)$ was measured on the basis of solar radiation $(G)$, gas power $\left(P_{g}\right)$ and airflow $(\dot{m})$. The measurements were carried out in steady state which was reached after two hours in case of solar mode and one hour in case of gas mode.

Figure 5 shows the variation of $\left(T_{c h}\right)$ on basis of $(G)$ varying in a range of $0-1200 \mathrm{~W} / \mathrm{m}^{2}$ while gas power and airflow are maintained constant at $\left(P_{g}=2 \mathrm{~kW}\right)$ and $(m=0.025 \mathrm{~kg} / \mathrm{s})$, respectively.

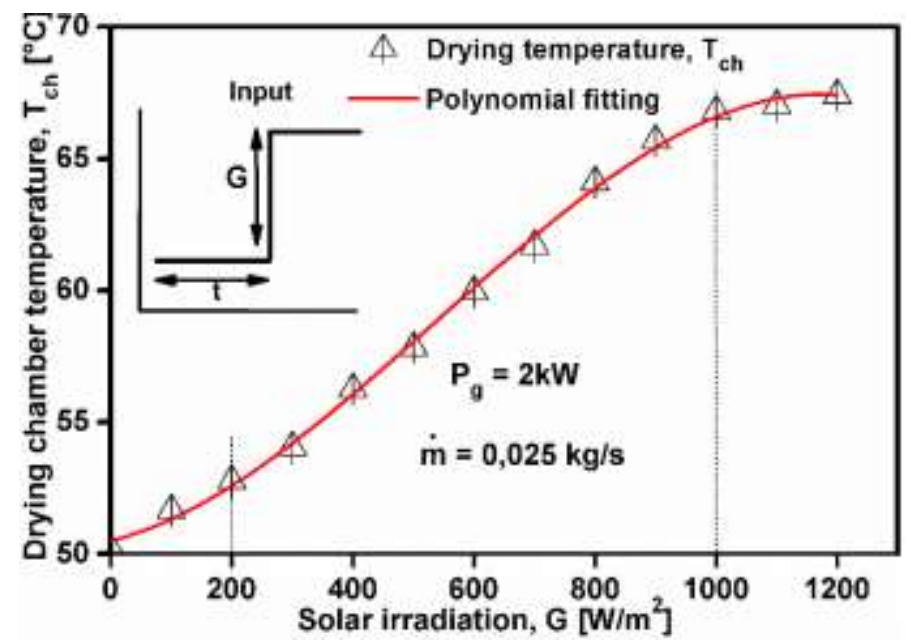

Figure 5. Static characteristic of the dryer on the basis of solar radiation. 
The static characteristic of $\left(T_{c h}\right)$ on basis of $\left(P_{g}\right)$ was built varying the gas power in a range of $(0-5 \mathrm{~kW})$ while considering solar radiation and airflow constant $\left(\mathrm{G}=700 \mathrm{~W} / \mathrm{m}^{2}\right.$ and $\left.\dot{m}=025 \mathrm{~kg} / \mathrm{s}\right)$ (Figure 6).

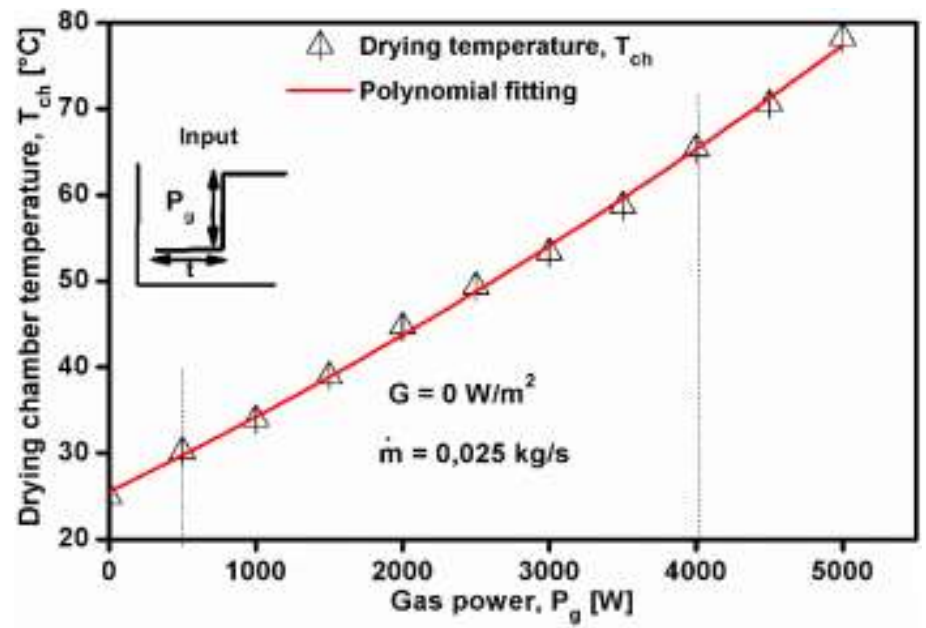

Figure 6. Static characteristic of the dryer on the basis of gas power.

The static characteristic of $\left(T_{c h}\right)$ on basis of $(\dot{m})$ was built varying the airflow in a range of $(0-0.07 \mathrm{~kg} / \mathrm{s})$ while considering solar radiation and gas power constant $\left(G=700 \mathrm{~W} / \mathrm{m}^{2}\right.$ and $\left.P_{g}=3 \mathrm{~kW}\right)$ (Figure 7).

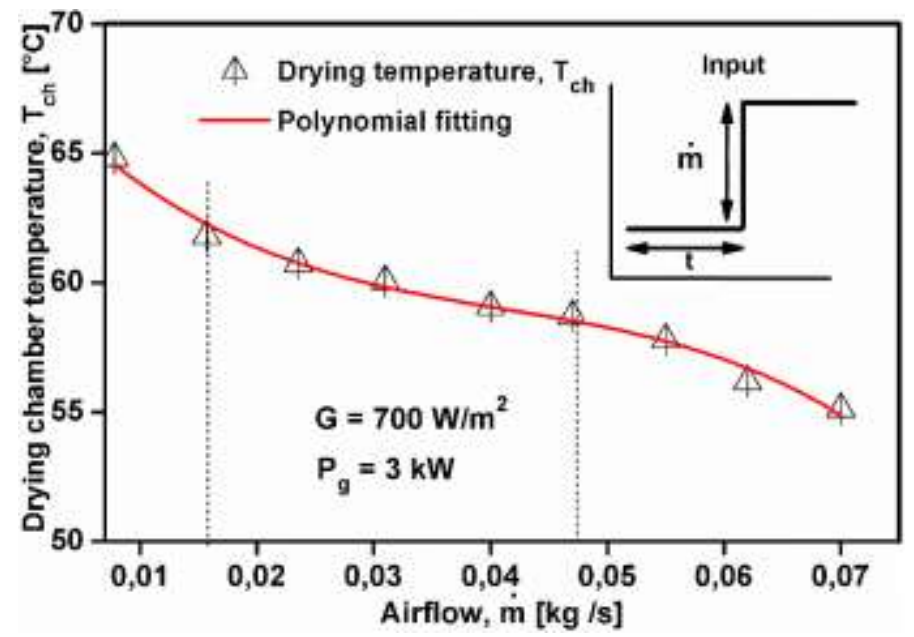

Figure 7. Static characteristic of the dryer on the basis of airflow.

After plotting the static characteristics of the dryer, linear zones were identified around many operating points. The linear zones in are identified taking into consideration the following assumptions:

The dryer is operated in the neighborhood of a limited set of operating points. The dryer stays near certain working point for a long time compared to the largest drying time. At each operating point, the dryer dynamics are time invariant and the change is extremely slow. At each operating point, the dryer behavior can be accurately approximated by linear model.

\subsection{Input Signals}

The used input tests signal for modeling the dryer are Pseudo Random Binary Sequences (PRBS). The PRBS is a two state signal varying between the maximum and the minimum points of each linear zone. In addition, at least one of the PRSB pulses width should be greater than the system rise time [26]. A 
transitory state simulation was carried out in order to calculate the rising time of the dryer applying step signals of solar radiation, gas power and airflow and the rising time for each response was noticed $\left(t_{\mathrm{rG}}=66 \mathrm{~min} ; \mathrm{t}_{\mathrm{rPg}}=21 \mathrm{~min} ; \mathrm{t}_{\mathrm{rm}}=27 \mathrm{~min}\right)$. Figure 8 depicts the generated input signals.
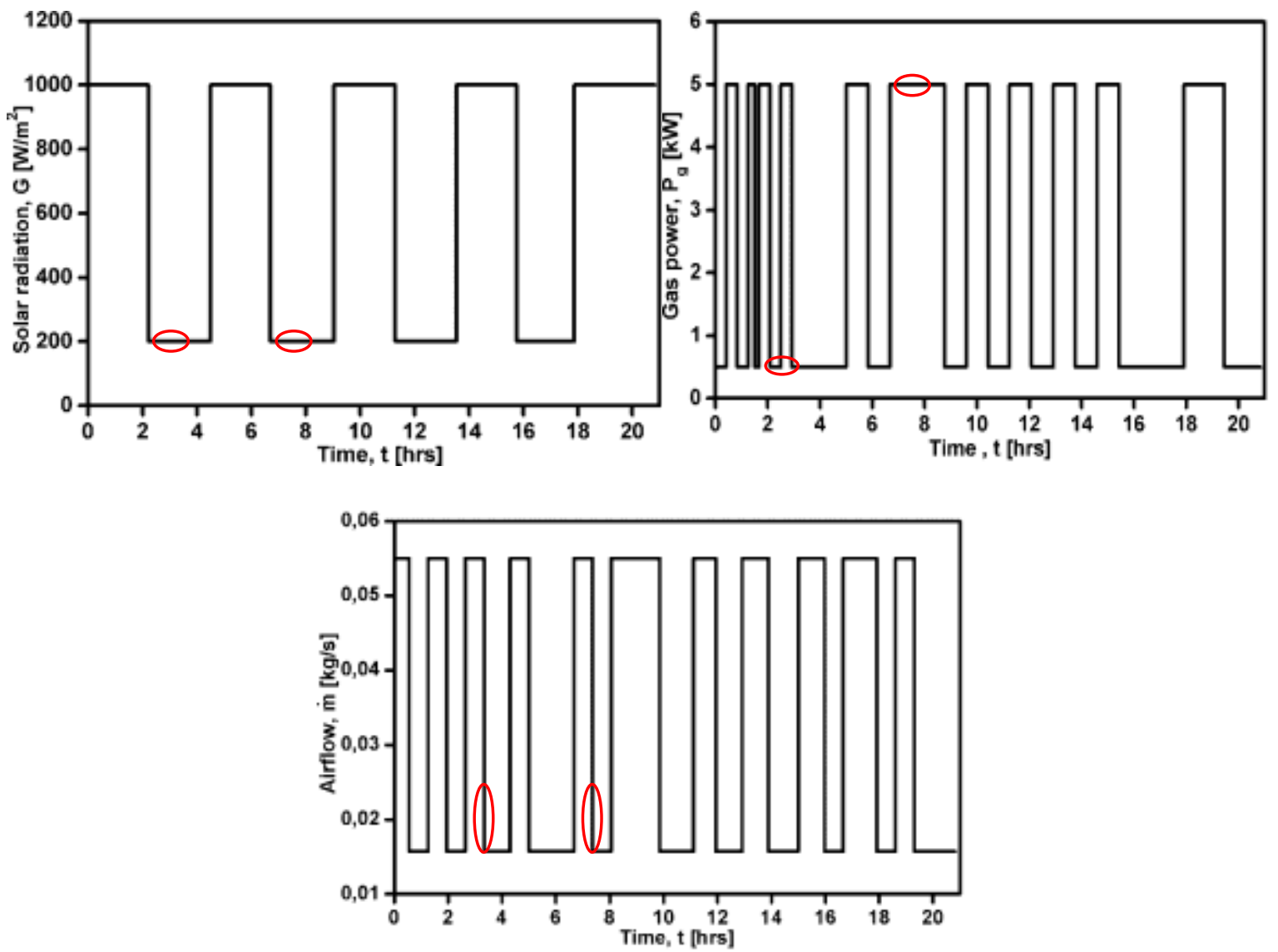

Figure 8. PRBS input signals.

\subsection{Multivariable Model of the Hybrid Solar-gas Dryer}

The generated input signals are applied to the dryer simultaneously using (dependence) function in SolidWorks. The simulations were conducted in transitory state. The simulation time was set to 20 hours of operation. But only 15 hours were considered for modeling, during this period the dynamic response of the dryer was well described. Figure. 9 shows the variation of the average drying temperature inside the drying chamber. It can be noticed from the Figure 8 slight variations in of the temperature in the steady state. This is due to airflow variation for the increasing and decreasing of drying temperature. Other sequences of PRBS input signals were generated and used for modeling and the same results were obtained. The calculation time for every simulation was huge and estimated at 21 days. 


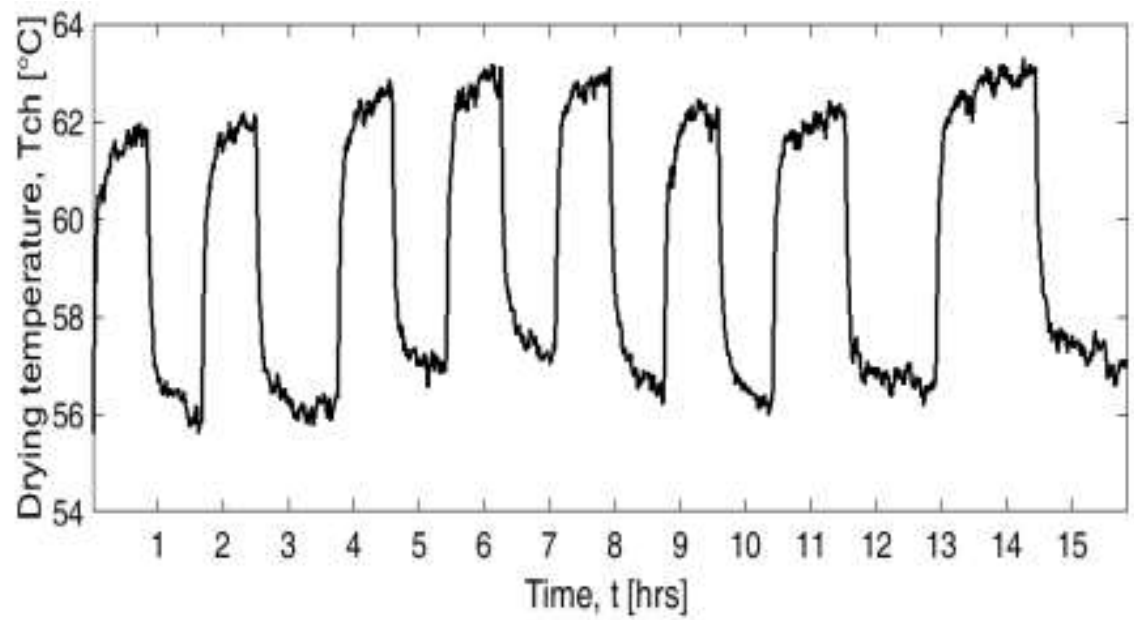

Figure 9. Variation of drying chamber temperature.

The obtained input/output data were loaded into the system identification Toolbox of Matlab environment using (Ident) in order to identify the linear model of the hybrid dryer. The system identification provided using Matlab allows building mathematical models of a dynamic system based on non-linear least squares estimation method.

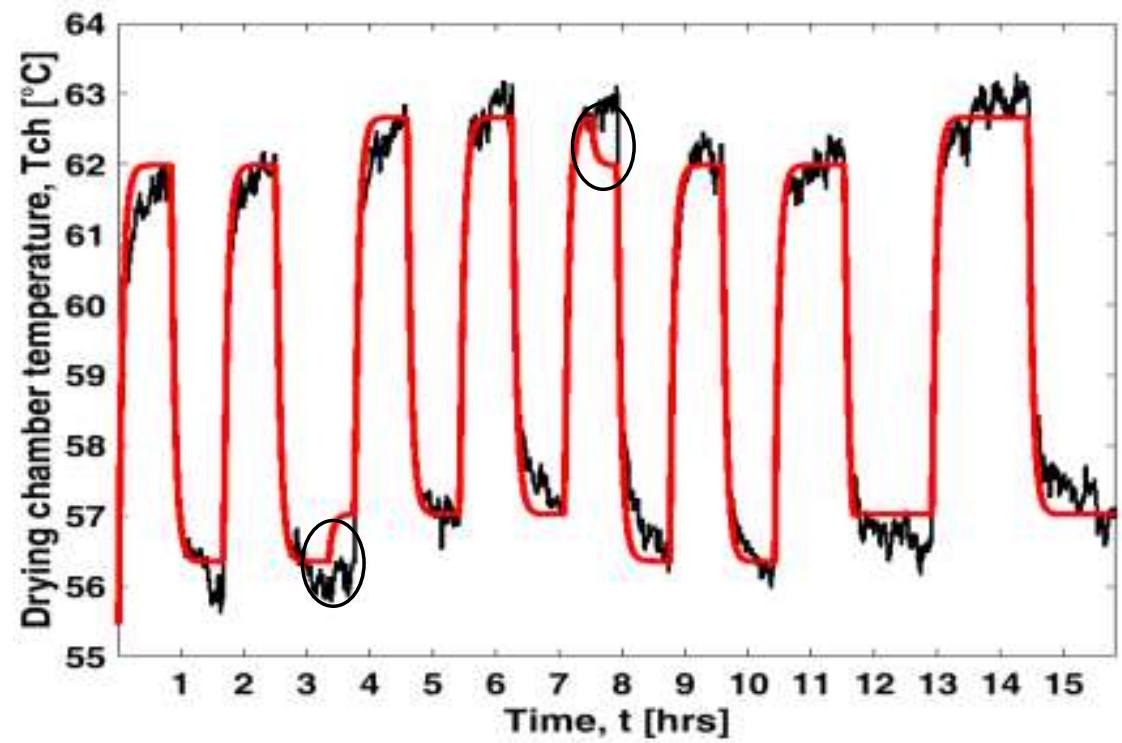

Figure 10. Simulated outputs of CFD and MM models.

The simulation results of the identified linear multivariable model fitted the CFD ones with $90 \%$ of accuracy. Slight distortion of the MM response was appeared in the durations (3.5-4h) and (7.5-8h) as shown in Figure 10. This is due to the abrupt shifting of airflow in both durations while solar radiation and gas power were constant as mentioned in Figures .8. Taking into consideration the tolerable temperature range uncertainty for dying several products $(+/-3)$ and for control purpose, this is an accurate model.

The hybrid dryer state space multivariable model is represented by:

$$
\begin{gathered}
A=\left[\begin{array}{ll}
-0.0030 & -0.0202 \\
-0.0141 & -0.1701
\end{array}\right] B=\left[\begin{array}{ccc}
-0.0004579 & 6.879 e^{-6} & 4.959 e^{-6} \\
-0.001803 & 2.66 e^{-5} & -0.0003882
\end{array}\right] \\
C=\left[\begin{array}{ll}
238.4 & -0.5692
\end{array}\right]
\end{gathered}
$$


Figure 11 shows the used Simulink blocks to represent the studied hybrid solar-gas dryer.

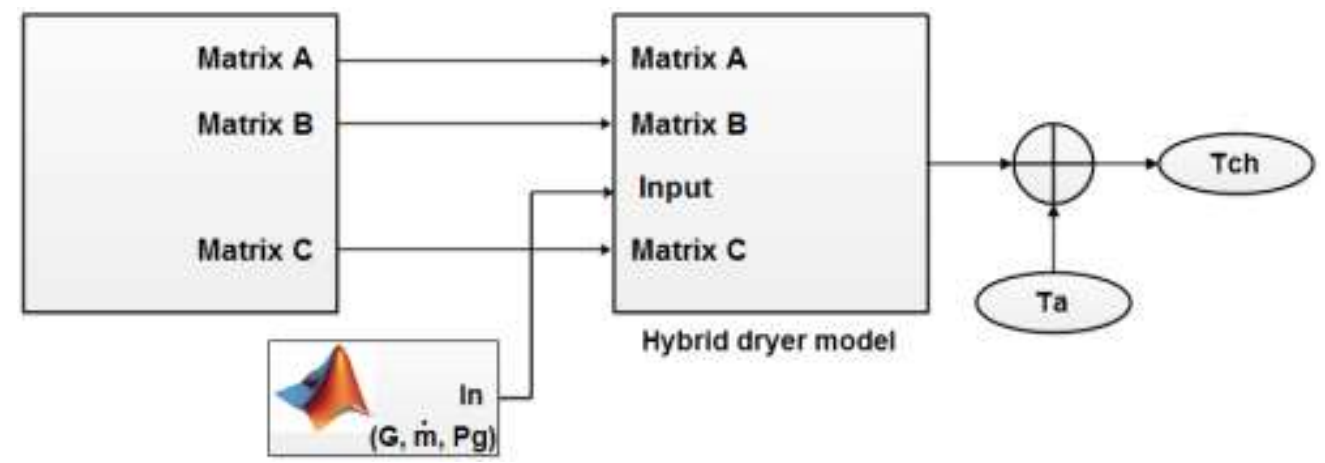

Figure 11. Multivariable model of hybrid solar-gas dryer.

The least squares method is a major tool models' parameters estimation using input-output data. This method is represented as a mathematical procedure by which the unknown parameters of a mathematical model are chosen (estimated) such that the sum of the squares of some chosen error is minimized. The used mathematical equations for estimating the model parameters are the following [24]:

$$
y(t)=G(t) \theta_{1}(t)+P_{g}(t) \theta_{2}(t)+\dot{m}(t) \theta_{3}(t)
$$

Where $y(t)$ is the output variable $\left(T_{c h}\right),\left\{\theta_{1}, \theta_{2}, \theta_{3}\right\}$ is a set of constant parameters, $G(t), P_{e}(t), \dot{m}(t)$ are input variables, the variable $t$ denotes time.

Assuming that $N$ samples of measurements of $y(t)$ and $G(t), P_{g}(t), \dot{m}(t)$ are made at time $1,2, \ldots, N$. Filling the data samples into Equ [5], results in a set of linear equations.

$$
y(t)=G(t) \theta_{1}(t)+P_{g}(t) \theta_{2}(t) \dot{m}(t) \theta_{3}(t) \quad t=1,2, \ldots, N
$$

This can be arranged in a simple matrix form:

$$
y=\emptyset \theta
$$

Where

$$
y=\left[\begin{array}{c}
y(1) \\
\vdots \\
y(N)
\end{array}\right], \quad \quad \varnothing=\left[\begin{array}{ccc}
G(1) & P_{g}(1) & \dot{m}(1) \\
\vdots & \vdots & \vdots \\
G(N) & P_{g}(N) & \dot{m}(N)
\end{array}\right], \quad \quad \theta=\left[\begin{array}{l}
\theta_{1} \\
\theta_{2} \\
\theta_{3}
\end{array}\right]
$$

For $N=n=3$, we have a unique solution

$$
\hat{\theta}=\emptyset^{1} y
$$

Provided $\emptyset^{1}$, the inverse of square matrix $\emptyset$, exists. $\hat{\theta}$ denotes the estimate of $\theta$.

Introduce a residual error, and then:

$$
\varepsilon(t)=y(t)-\hat{y}(t)=y(t)-\varphi(t) \theta
$$

$\hat{\theta}$ is chosen such that the criterion: 


$$
V_{L S}=\frac{1}{N} \sum_{t=1}^{N} \varepsilon(t)^{2}=\frac{1}{N} \sum_{t=1}^{N}[y(t)-\varphi(t) \theta] \varepsilon^{2}=\frac{1}{N} \varepsilon^{T} \varepsilon
$$

is minimized. Here:

$$
\varepsilon=\left[\begin{array}{c}
\varepsilon(1) \\
\varepsilon(2) \\
\vdots \\
\varepsilon(N)
\end{array}\right]
$$

To carry out the minimization, we express:

$$
V_{L S}(\theta)=\frac{1}{N}(y-\emptyset \theta)^{T}(y-\emptyset \theta)=\frac{1}{N}\left[y^{T} y-\theta^{T} \emptyset^{T} y-y^{T} \emptyset \theta-\theta^{T} \emptyset^{T} \emptyset \theta\right]
$$

Taking the first derivative of $V_{L S}(\theta)$ with respect to $\theta$ and equating the result to zero, we have:

$$
\frac{\partial V_{L S}(\theta)}{\partial \theta}=\frac{1}{N}\left[-2 \emptyset^{T} y+2 \emptyset^{T} \emptyset \hat{\theta}\right]
$$

Hence the solution is given by the Equ [13].

$$
\emptyset^{T} \emptyset \widehat{\theta}=\emptyset^{T} y
$$

Or:

$$
\hat{\theta}=\left[\emptyset^{T} \emptyset\right]^{-1} \emptyset^{T} y
$$

$\hat{\theta}$ is least-squares estimator of $\theta$.

\section{RESULTS AND DISCUSSIONS}

\subsection{CFD Simulation of the Temperature and Airflow Distribution Inside the Hybrid Solar-gas Dryer.}

The temperature profiles inside the drying chamber at two operating modes of the hybrid solar-gas dryer (solar mode and gas mode) are shown in Figures (12-13), respectively.

\subsection{Solar Mode}

In the case of solar mode, the simulations were established in clear whole day of operation. The reached average drying chamber temperature is $45^{\circ} \mathrm{C}$ at an average solar radiation of $914.2 \mathrm{~W} / \mathrm{m}^{2}$ with an air flow of $0.025 \mathrm{~kg} / \mathrm{s}$. The drying temperature profile during a whole day of operation is shown in (Figure. $12)$. 


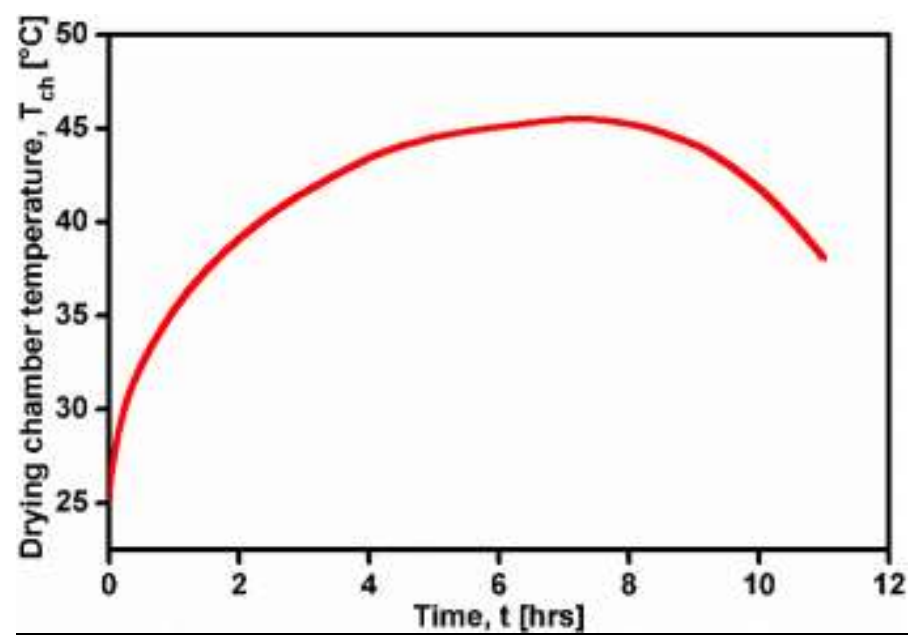

Figure 12. Temperature profile inside the drying chamber

The used solar radiations in simulations were measured experimentally using Keep and Zonen pyranometer. The solar radiations and ambient temperatures during the experiments are shown in Table 3.

Table 3. Solar radiation during experiments carried on December 16, 2016.

\begin{tabular}{ccc}
\hline Time & Solar radiation $\left(\mathrm{W} / \mathrm{m}^{2}\right)$ & Ambient temperature $\left({ }^{\circ} \mathrm{C}\right)$ \\
\hline $8 \mathrm{~h}$ & 360 & 21.3 \\
$9 \mathrm{~h}$ & 610 & 23.5 \\
$10 \mathrm{~h}$ & 720 & 24.3 \\
$11 \mathrm{~h}$ & 844 & 25.8 \\
$12 \mathrm{~h}$ & 920 & 26.6 \\
$1 \mathrm{~h}$ & 928 & 27.5 \\
2h & 947 & 28.3 \\
$3 \mathrm{~h}$ & 873 & 28.9 \\
$4 \mathrm{~h}$ & 747 & 27.4 \\
$5 \mathrm{~h}$ & 504 & 26.3 \\
$6 \mathrm{~h}$ & 181 & 24.7 \\
\hline
\end{tabular}

\subsection{Gas Mode}

In the case of intermittency of solar radiation at night or during inclement weather, the auxiliary gas heating system turns on. The average chamber temperature was investigated at different gas powers. It is observed that the average drying temperature inside the drying chamber are $33.6^{\circ} \mathrm{C}, 53.7^{\circ} \mathrm{C}$ and $70.2^{\circ} \mathrm{C}$ for gas powers of $1 \mathrm{~kW}, 3 \mathrm{~kW}$ and $4 \mathrm{~kW}$, respectively, as shown in Figure 13 . The steady state was reached quickly after approximately 16 min comparing with the solar mode (66 min) which confirm the effectiveness of the hybridization of the dryer using gas power. In addition, the ranges of the reached temperatures are suitable for drying a wide variety of agriculture products. 


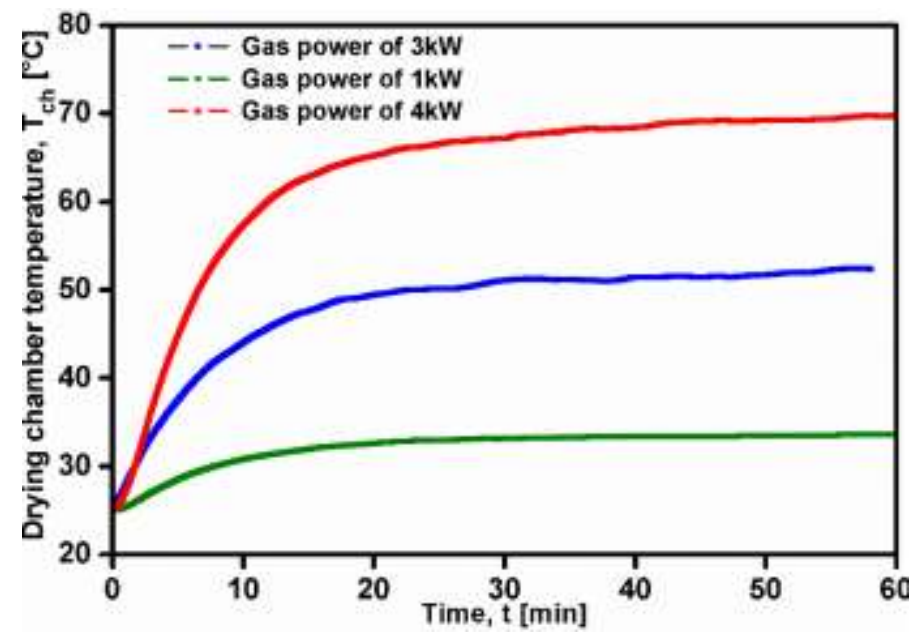

Figure 13. Temperature profile inside the drying chamber in a gas mode: a) Drying temperature, b) airflow path lines.

\subsection{Comparison Between CFD and Multivariable Modeling}

To check the effectiveness of the proposed multivariable model, the temperature delivered by CFD simulation is investigated with regard to the temperature predicted by multivariable model at two operating modes (solar mode and gas mode). CFD and MM simulation results are plotted against clock time as shown in Figs. (14a-14b). it is clearly shown that the simulation results of the drying temperature obtained from CFD slightly over-estimate the temperature predicted by (MM). The error estimation is slightly high in the transitory state while it tends to decrease in steady state. This is due the errors of linearization.
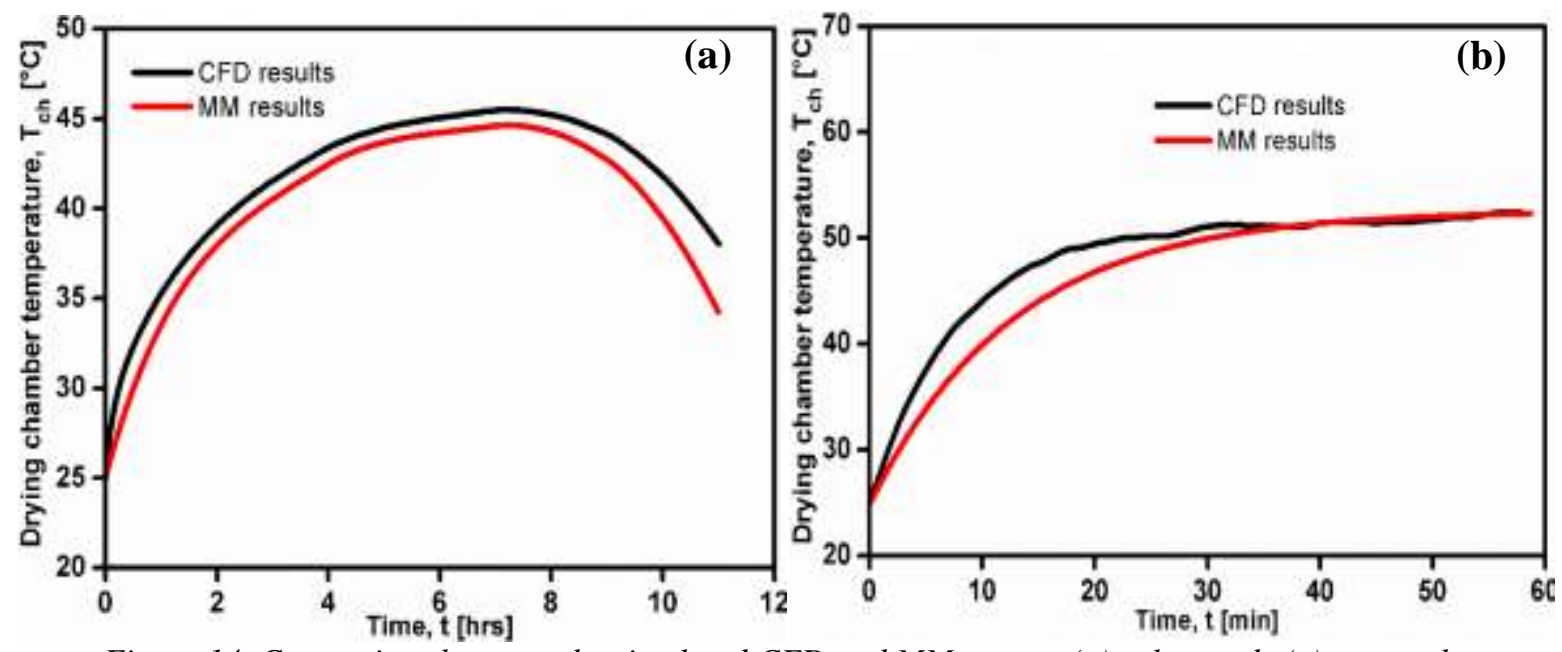

Figure 14. Comparison between the simulated CFD and MM output; (a) solar mode (c) gas mode.

The variation effect of solar radiation, gas power and airflow on the MM simulation results is also investigated and compared with the CFD simulations and the results are summarized in Table 4 . The CFD simulations were established in steady state. 
Table 4. Effect of solar radiation, gas power and airflow on the CFD and MM simulation results

\begin{tabular}{lccc}
\hline Solar radiation $\left(\mathrm{W} / \mathrm{m}^{2}\right)$ & $\mathrm{CFD}$ simulation & MM simulation & Relative error $(\%)$ \\
\hline 100 & $51.68^{\circ} \mathrm{C}$ & $52.1^{\circ} \mathrm{C}$ & 0.8 \\
200 & $52.79^{\circ} \mathrm{C}$ & $53.7^{\circ} \mathrm{C}$ & 1.7 \\
300 & $54.04^{\circ} \mathrm{C}$ & $55.44^{\circ} \mathrm{C}$ & 2.5 \\
400 & $57.25^{\circ} \mathrm{C}$ & $56.78^{\circ} \mathrm{C}$ & 0.8 \\
500 & $57.84^{\circ} \mathrm{C}$ & $58.11^{\circ} \mathrm{C}$ & 0.4 \\
600 & $58.96^{\circ} \mathrm{C}$ & $59.46^{\circ} \mathrm{C}$ & 0.8 \\
700 & $60.69^{\circ} \mathrm{C}$ & $60.76^{\circ} \mathrm{C}$ & 0.1 \\
800 & $63.12^{\circ} \mathrm{C}$ & $62.56^{\circ} \mathrm{C}$ & 0.88 \\
900 & $64.69^{\circ} \mathrm{C}$ & $63.8^{\circ} \mathrm{C}$ & 1.3 \\
1000 & $65.81^{\circ} \mathrm{C}$ & $65.1^{\circ} \mathrm{C}$ & 0.07 \\
\hline $\mathrm{Gas} \mathrm{power}(\mathrm{kW})$ & & & \\
0.5 & $30.24^{\circ} \mathrm{C}$ & $29.6^{\circ} \mathrm{C}$ & 2.1 \\
1 & $33.95^{\circ} \mathrm{C}$ & $33.09^{\circ} \mathrm{C}$ & 2.5 \\
1.5 & $38.99^{\circ} \mathrm{C}$ & $37.68^{\circ} \mathrm{C}$ & 3.35 \\
2 & $43.38^{\circ} \mathrm{C}$ & $42.27^{\circ} \mathrm{C}$ & 2.5 \\
2.5 & $47.38^{\circ} \mathrm{C}$ & $46.86^{\circ} \mathrm{C}$ & 1.09 \\
3 & $52.33^{\circ} \mathrm{C}$ & $51.56^{\circ} \mathrm{C}$ & 1.4 \\
3.5 & $55.19^{\circ} \mathrm{C}$ & $56.04^{\circ} \mathrm{C}$ & 1.5 \\
4 & $61.4^{\circ} \mathrm{C}$ & $60.63^{\circ} \mathrm{C}$ & 1.2 \\
5 & $67.27^{\circ} \mathrm{C}$ & $68.4^{\circ} \mathrm{C}$ & 1.6 \\
\hline Airflow (kg/s) & & & \\
0.0072 & $64.12^{\circ} \mathrm{C}$ & $62.8^{\circ} \mathrm{C}$ & 2.05 \\
0.025 & $60.07^{\circ} \mathrm{C}$ & $60.35^{\circ} \mathrm{C}$ & 0.4 \\
0.047 & $58.71^{\circ} \mathrm{C}$ & $59.4^{\circ} \mathrm{C}$ & 1.17 \\
0.062 & $56.18^{\circ} \mathrm{C}$ & $58.6^{\circ} \mathrm{C}$ & 4.3 \\
\hline
\end{tabular}

The temperature profile of CFD simulation is almost similar to MM temperature profile. The root main square error RMSE is used for validation of CFD simulation results against MM ones and given in Table 5 .

Table 5. Statistically validation of simulation results

\begin{tabular}{lc}
\hline Operating mode & Root mean square of percent deviation \\
\hline Solar mode & 2.60 \\
Gas mode & 2.11 \\
Irradiance variation & 0.71 \\
Gas variation & 0.91 \\
Airflow variation & 1.42 \\
\hline
\end{tabular}

The higher difference between the MM and CFD results is $2.3^{\circ} \mathrm{C}$. The relative error remains under $3.35 \%$ and the RMSE varies from 0.71 to 2.60 which shows the good strength of the modeling method and the closeness of the CFD simulation results with MM ones. A notable reduction in simulation time was also noticed. The simulation time is reduced from several hours to less than one second.

\section{CONCLUSIONS}

The solar dryer operates under unstable and random input parameters (solar radiation, ambient temperature and ambient relative humidity). Controlling such device requires developing an accurate model to predict instantly the output parameters (drying air temperature). The threshold of drying temperature has been investigated using CFD model in three operating modes of the dryer (solar mode, gas mode and hybrid mode) and the range of the reached temperatures are suitable for drying a wide variety of products. The present model will be beneficial to design solar-gas hybrid dryer for drying 
products without incurring any damages or alteration of their quality by flues gases. Nevertheless, the CFD simulation time for each weather condition is so important which hinders any control of the dryer. Thus, a multivariable model of the hybrid dryer for predicting the drying temperature was developed based on nonlinear least squares methods taking into account solar radiation, gas power and airflow as the main input parameters. The predicted temperatures by multivariable model were compared with the CFD ones based on mean root square error (RMSE) and relative error. From the values of RMSE (0.712.60) and relative error (under 3.35\%), it is inferred that the predicted values by MM are in harmony with the observed values by CFD in two operating modes. The multivariable model leads to predict the temperature instantly with a remarkable reduction in simulation time.

\section{Acknowledgment}

This work was supported by the research institute for solar energy and new energies (IRESEN) as part of the project SSH. The authors are grateful to the IRESEN institute for its cooperation.

\section{REFERENCES}

[1] Chauhan, S, P, Kumar, A, Tekasakul, P. Application of software in solar drying systems: A review. Renewable and Sustainable Energy Review 2015; 51: 1326-1337.DOI: https://doi.org/10.1016/j.rser.2015.07.025

[2] Azaizia, Z, Kooli, S, Elkhadraoui, A, Hamdi, I. Investigation of a new solar greenhouse drying system for peppers. Int. J. Hydrogen Energy 2017; 42: 8818-8826. DOI: https://doi.org/10.1016/j.ijhydene.2016.11.180

[3] Aghbashlo, M, Muller, J, Mobli, J, Madaldou, A, Rafiee, S. Modeling and simulation of deep-bed solar greenhouse drying of Chamomile flowers. Drying Technology 2015; 33: 684-695. DOI: https://doi.org/10.1080/07373937.2014.981278.

[4] Aghbashlo, M, Kianmehr, MN, Samimi-Akhijahani, H. Influence of drying conditions on the effective moisture diffusivity, energy of activation and energy consumption during the thin-layer drying of berberis fruit (Baerberidaceae). Energy Conversion and Management 2008; 49(10): 2865-2871. DOI: https://doi.org/10.1016/j.enconman.2008.03.009

[5] Boughali, S, Benmoussa, H, Bouchekima, B, Mennouch, D, Bouguettaia, H, Bechki, D. Crop drying by indirect active hybrid solar-electrical dryer in the eastern Algerian Septentrional Sahara. Solar Energy 2009; 83(12): 2223-2232. DOI: https://doi.org/10.1016/j.solener.2009.09.006.

[6] Belloulid, M.O., Hamdi, H, Mandi, L, Ouazzani, N., Solar drying of wastewater sludge: a case study in Marrakesh, Morocco. Environmental Technology (United Kingdom) 2018; 1-7. DOI: 10.1080/09593330.2017.1421713.

[7] Adams, RL, Thompson, JF. Improving drying uniformity in concurrent flow tunnel dehydrator. Transaction of ASAE 1985; 23(3): 890-892. DOI: 0001-2351/85/2803-0890\$0.00

[8] Raouzeos, GS, Saravacos, GD. Solar drying of raising. Drying Technology 1986; 4(4): 633-649. DOI: https://doi.org/10.1080/07373938608916353.

[9] Amer, BMA, Hossain, MA, Gottschalk, K. Design and performance evaluation of a new hybrid dryer for banana. Energy Conversion and Management 2010; 51: 813-820. DOI: https://doi.org/10.1016/j.enconman.2009.11.016.

[10] TadahmumYassen, A, Hussain Al-Kayiem, H. Experimental investigation and evaluation of hybrid solar/thermal dryer combined with supplementary recover dryer. Solar Energy 2016; 134: 284-293. DOI: https://doi.org/10.1016/j.solener.2016.05.011.

[11] Lopez-Vidana, E, Mendez-Laguna, L, Rodriguez-Ramirez, J. Efficiency of a hybrid solar-gas dryer. Solar Energy 2013; 93: 23-31. DOI: https://doi.org/10.1016/j.solener.2013.01.027.

[12] Oueslati, H, Benmbrouk, S, Mami, A. Design and installation of a solar-gas tunnel dryer. The 5th Int. Renewable Energy Congress IREC 2014; 1-9. DOI: 978-1-4799-2195-9/14/\$31.00.

[13] Junchangpood, A, Chanvattana, V. A simulation of temperatures and velocities distribution of a hot-air steam of a rubber smoke sheet drying room using CFD. Conf. Mech. Eng. Netw. Thail 2007; 24: 1041-1047.

[14] Tekasakul, P, Promtong, M. Energy efficiency enhancement of natural rubber smoking process by flow improvement using a CFD technique. Applied Energy 2008; 85(9): 878-895. DOI: https://doi.org/10.1016/j.apenergy.2008.02.004. 
[15] Promtong, M, Tekasakul, P. CFD study of flow in natural rubber smoking room: I. Validation with the present smoking-room. Appl. Therm. Eng 2007; 27: 2113-2121. DOI: https://doi.org/10.1016/j.applthermaleng.2006.11.009.

[16] Dejchanchaiwong, R, Tirawanichakul, Y, Tirawanichakul, S, Tekasakul, P. Single-phase and multiphase models for temperature and relative humidity calculations during forced convection in a rubber-sheet drying chamber. Maejo Int. J. Sci. Technol 2014; 8(2): 207-220. DOI: 10.14456/mijst.2014.29.

[17] Sonthikun, S, Chairat, P, Fardsin, K, Kirirat, P, Kumar, A, Tekasakul, P. Computational fluid dynamic analysis of an innovative design of solar-biomass hybrid dryer: An experimental validation. Renewable Energy 2016; 92: 185-191. DOI: https://doi.org/10.1016/j.renene.2016.01.095.

[18] Kumar, A, Tiwari, GN. Thermal modeling of a natural convection greenhouse drying system for jiggery: an

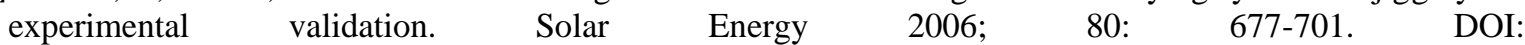
https://doi.org/10.1080/14786451.2012.724070.

[19] Tiwari, G.N., Das, T., Chen, C.R., Barnwal, P. Energy and Exergy analysis of greenhouse fish drying. Int J Exergy 2009; 6: 620-636. DOI: https://doi.org/10.1504/IJEX.2009.027493.

[20] Prakash, O., Kumar, A. ANFIS modeling of a natural convection greenhouse drying system for jiggery: experimental validation. Int. J. Sustain Energy 2014; 33: 316-335. DOI: https://doi.org/10.1080/14786451.2012.724070.

[21] Ferouali, H.E., Doubabi, S., Kouhila, M., Abdenouri, N. Modelling of flat plate and V-corrugated solar air heaters operated in natural and forced convection. In: Proceedings of ECOS 2015: 28th Int. Conf. Efficiency, Cost, Optimization, Simulation and Environmental Impact of Energy Systems; 2015 June 30-july 3; Pau, France.

[22] Ferouali, H.E., Doubabi, S., Kouhila, M., Abdenouri, N. Modelling of flat plate and V-corrugated solar air heaters for single and counter flow operating modes. In: Proceedings of IEEES7: 7th International Exergy, Energy and Environment Symposium; 2015 April 27-30; Valenciennes, France.

[23] Beid, S.E., Doubabi, S. DSP based implementation of fuzzy output tracking control for a boost converter. IEEE transaction on industrial electronics 2014; 61: 196-209. DOI: 10.1109/TIE.2013.2242413.

[24] Nouri, A, Salhi, I, Elwarraki, E, Beid, S.E., Essounbouli, N. DSP based implementation of a self-tuning fuzzy controller for three level boost converter. Electric power systems Research 2017; 146: 286-297. DOI: https://doi.org/10.1016/j.epsr.2017.01.036.

[25] Zhu, Y. Multivariable System Identification for Process control. Elsevier Sciences and Technology Books $2001 ; 349$.

[26] Landau, I.D., System Identification and Control. Paris: HERMES Edition, 1993. 